\title{
Employee Engagement among IT Employees during COVID-19
}

\author{
Swathi Jampala \\ Assistant Professor \\ AMS School of Informatics, OU Road, Hyderabad
}

\begin{abstract}
In the present business circumstances during the COVID-19 pandemic, employee engagement has become one of the utmost prominent priorities for human resource managers and practitioners in organizations due to lockdown. In the pandemic situation to survive and gain a competitive advantage in today's fast changing work environment, competitive pressures, and stakeholders demands, organizations attribute more importance to their workforce. The paper is to determine the engagement of employees by IT companies during corona virus pandemic. Data will be collected through self-administered questionnaire from the IT employees. Organizations currently are regularly developing innovative and effective means to engage the employees during this tough time. Works from home system engagement activities are very fruitful for employees as well as for organizations. Those organizations doing these categories of engagement activities for their employees in the process of learning new skills and developing themselves. Employees are feeling committed to the organization and stay motivated during this tough time of COVID-19 pandemic.
\end{abstract}

Keywords: Employee Engagement, Human Resource Management, Information Technology Companies, COVID-19

\section{Introduction}

The major importance of employee engagement has been felt by many organizations in recent decades. The inception of the year 2020 brought a good grave need for strengthening the engagement level of employees due to COVID-19 crisis and lockdown worldwide. The entire globe is under the grip of COVID-19 crisis. Its impact are often felt not only on the health of a private but on the general health of a corporation. Where many organizations had to accept the notice of employees, existing employees are depicting lower level of employee engagement. Big corporate houses are struggling to be a minimum of stagnant if not succeeding during COVID-19, while many not-so-big corporate houses are on the verge of complete shutdown. Such unprecedented situation has created trepidation among the workforce associated with their job security, bonuses, and performance appraisals then on. Thus, their reduced engagement level is clear.

\section{Need of the Study}

When the economy's in terrible shape, any folks is lucky to possess employment, human resources managers worrying about whether or not employees are contributing to the organizational goals and objectives, and the way to pursue the recruitment and selection process, employee's engagement, and, training and development activities, these are the present human resource management challenges which are created due to COVID-19 pandemic. Organizations round the world face a troublesome situation, first time in history, the price of one-barrel oil fell to but nothing on $20^{\text {th }}$ April 2020, the only reason is behind this is often the present lockdown round the world. The physical place of work is converted into a virtual workplace, now the HR managers are planning the way to engage the workers efficiently. This study pursued to look at the effect of employee's engagement on organizational performance through the mediating effect of data sharing for workers of upper educational institutions.

\section{Objectives of the Study:}

1. To look at the impact of data sharing on organization performance.

2. Tostudy the mediating impact of data sharing between employee engagement and organizational performance. 


\section{Research Methodology}

This study was conducted among IT and ITEs employees in different companies. The sample size consists of 50 respondents namely working who were chosen based on simple random sampling technique. The study was based on both primary and secondary sources of information. Data analysis done through graphical representation.

\section{Review of literature}

Job satisfaction may be a significant driver of labor engagement. As per Garg, Dar, and Mishra (2017) result revealed that there's a positive relationship between job satisfaction and work engagement. Further analysis showed that employee job satisfaction results in employee engagement. Employee engagement link to financial performance comprising revenue growth, profit margins, shareholder return, and operating income is nearly 3 times greater than organizations with disengaged personnel. It also elaborates that higher employee engagement level leads to lower absenteeism and job stress and better well-being and health. Further research shows that employee engagement has an impact on a company's bottom line and is sturdily linked to business performance (Saks, 2017). Engaged employees have emotional association with their work as well as their organization. Engaged employees always trust within the leaders of the organization. Hence, engaged employees are more dedicated and committed toward their work also as organization. Engaged personnel are always optimistic, keep good interpersonal rapport with each other, and also show high level of performance in the organization (Jena, Pradhan, \& Panigrahy, 2018). As per Tiwari and Lenka (2019) revealed that functional, economic, and psychological benefits upsurge employees' level of engagement. Results indicate that internal corporate communication, perceived communication satisfaction, knowledge sharing, continuous learning, and intrapreneurship were positively related to employee engagement. This paper found that if organizations invested in their human resources and building complete human resource management (HRM) system in their organization, it produces an engaged personnel, and, in return, organizations improve their performance (Tensay\& Singh, 2020). Employees those dispositional happiness experience at higher level always practice higher levels of employee engagement (Barreiro \&Treglown, 2020). Employee engagement is critical for a corporation to retain their valued employees. It is very essential for a corporation to try to to effective utilization of human resources in a corporation. Without employee engagement, a corporation cannot survive for a lengthy period.

\section{Employee engagement is important during tough times}

Schmidt et al. proposed a bridge between the pre-existing concept of 'job satisfaction' and employee engagement with the definition: "an employee's involvement with, commitment to, and satisfaction with work. Employee engagement is a part of employee retention." This definition integrates the classic constructs of job satisfaction (Smith et al., 1969), and organizational commitment (Meyer \& Allen, 1991).

According to the American Management Association, engagement levels are often improved, even throughout the tough periods, if companies lookout and make the proper decisions at the proper time. According to the study, higher engagement levels are linked to improved productivity and a healthier bottom line. In good times or bad, worker engagement should be a top priority of organizations.

\section{Drivers of engagement}

Some additional points from research into drivers of engagement are presented below:

Employee's Personal Resources - "... it is found that the positive perceptions that individuals hold of their own personal strength and ability allow them to be engaged with the organization."

Employee Perceptions of Job Importance - "...an employee's attitude toward the job's importance and the company had the greatest impact on loyalty and customer service than all other employee factors combined." 
Employee Clarity of Job Expectations - "If expectations are not clear and basic materials and equipment are not provided, negative emotions such as boredom or resentment may result, and the employee may then become focused on surviving quite brooding about how he can help the organization succeed."

Career Advancement/Improvement Opportunities - "Plant supervisors and managers indicated that many plant improvements were being made outside the suggestion system, where employees initiated changes in order to reap the bonuses generated by the next cost savings."

Regular Feedback and Dialogue with Superiors - "Feedback is the key to giving employees a sense of where they're going, but many organizations are remarkably bad at giving it."

Quality of Working Relationships with Peers, Superiors and Subordinates - "... if employees' relationship with their managers is fractured, then no amount of perks will persuade the employees to perform at top levels. Employee engagement may be a direct reflection of how employees feel about their relationship with the boss."

Perceptions of the Ethos and Values of the Organization - "Inspiration and values' is the most important of the six drivers in our Engaged Performance model. Inspirational leadership is the ultimate perk. In its absence, [it] is unlikely to interact employees."

Effective Internal Employee Communications - which convey a clear description of "what's going on". Commitment theories are rather supported creating conditions, under which the worker will feel compelled to figure for a corporation, whereas engagement theories aim to cause a situation in which the worker by free choice has an intrinsic desire to figure within the best interests of the organization.

Various companies do employee engagement practices during a very innovative and artistic manner to stay their employees satisfied and committed toward the organization. It is very essential to try to to employee engagement practices during this difficult time of the pandemic.

Essentials of Employee Engagement - "Organizations understand the importance of employee engagement, clearly see its benefits, but fail to act on it. This inaction is responsible for low engagement levels at many organizations. We will check out some employee engagement ideas and activities that you simply may try at your organization."

Before we glance at some employee engagement ideas, let's understand how we will make your employee engagement initiative a hit.

\section{Let the Employees Know the Importance of Employee Engagement}

Engaged or not, employees clearly got to understand what it's and what it could mean for them at work. If you propose to proactively start and measure employee engagement initiatives, your employees should know all about it. You need to be clear in conveying what it means for them and how they stand to benefit. You should equally involve employees and their managers within the process. Not only is it important to involve your employees, but also keep them informed of all developments. One must remember that engagement cannot, and cannot be driven by just one department. All departments need to be a part of employee engagement ideas and activities.

\section{Role and Expectations}

The employers, also because the employees, got to be beyond what's expected of them, and their role in successfully executing employee engagement initiatives. This is a time-intensive process and requires equal participation from all stakeholders to make it a success, there is no magic formula. 


\section{Set up a Team}

You can start-off by involving all function managers or heads alongside your core HR team, this can't be entirely driven by HR. You may diversify the team as you see fit, rather we encourage more involvement. Bigger participation brings about more and better ideas.

\section{Define Objectives}

You need to line clear objectives for your employee engagement initiative and you want to meet at fixed intervals for status updates. Core objectives can be decided on roles, functions, levels of experience. Clear objectives will render effective results and convey direction to your employee engagement ideas and activities.

\section{Data}

There are many tools available within the market to assist you conduct surveys, gather data and run various sorts of analyses. Collecting and analyzing data should be the primary step in your action plan. It not only helps you understand the established order, but also helps in making informed decisions, and devising strategic next steps. Data gives direction to your plan and also helps you create comparisons, which comes in handy to measure the effectiveness of latest activities. Sharing of data with the management team and Heads of Department (HODs) will bring about awareness and suggestions to revamp processes. It also helps in identifying trends about employee dissatisfaction, exits, etc.

\section{Employee Engagement Activities \\ Striking the Right Work-Life Balance}

This is tough since this may be something unique to each employee, and you've got to understand that each employee is exclusive then are their needs. Managers and HR reps can work with employees for this, and creating a versatile work schedule may be a great way to start out.

\section{Check Your Workplaces, Weekly Pulse}

Weekly Pulse is one among the foremost heavily used Workforce features. It's a fast, direct and straightforward question asked employees to urge an easy understanding of their mood and morale. In other words, it's an employee sentiment analysis.

Workforce provides you with clear and crisp dashboards that combine deep analytics with powerful insights oriented towards enabling you to require action within the sort of employee engagement ideas and activities. Why don't you check in and check out the portal for yourself?

\section{Training Needs}

Providing regular training to all your employees is essential, it fosters their growth. You may plan these for a few employees or do for teams. Managers can help design these training sessions, asking your employees directly is also a great way to ensure they get what they want and need.

\section{Career-pathing}

No matter the character of the work or seniority of the workers, everyone should be absolutely clear about their growth path. They need to understand and understand their future roles and responsibilities and the way they will get there.

\section{Communication is Key}

Employees got to feel safe about communicating their thoughts, be it new ideas or grievances. Feedback if heard and acted upon instills confidence about the management within the employees, a key reason for them to remain longer with the association.

\section{Conduct Cross-team Benchmarking Surveys}

while every employee is unique, they do work in teams. And sometimes being part of a team can influence the way employees think and feel. 


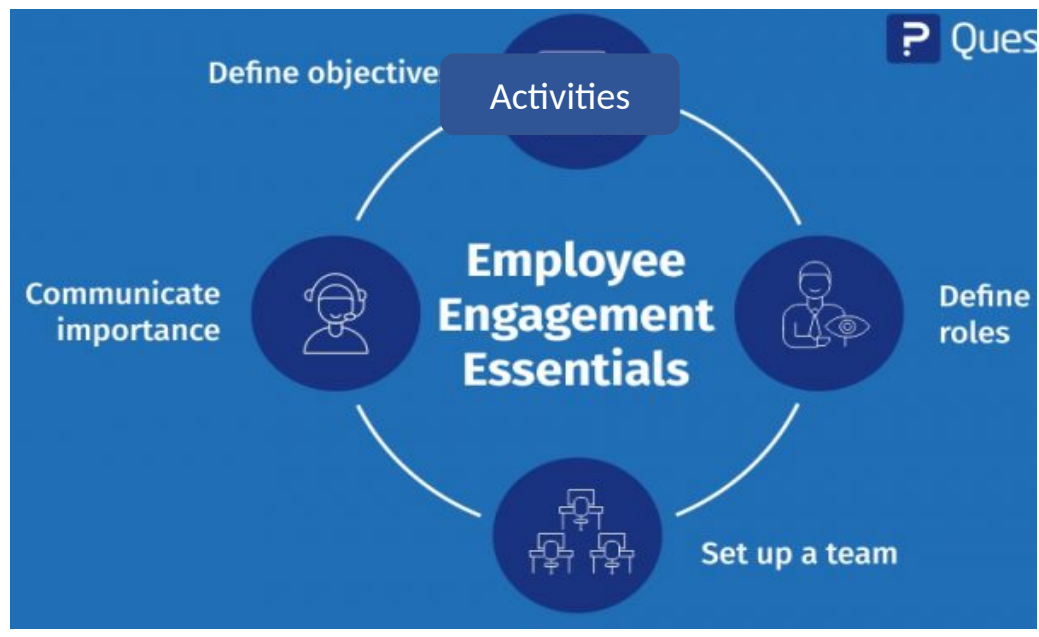

\section{Data Analysis and Interpretation}

1. Does your manager demonstrates an interest in your well-being?

\section{Manager demon- strates an interest} in your well-being

2. Does your manager sets clear expectations for your performance?



3. Do you feel comfortable in giving feedback to your manager?

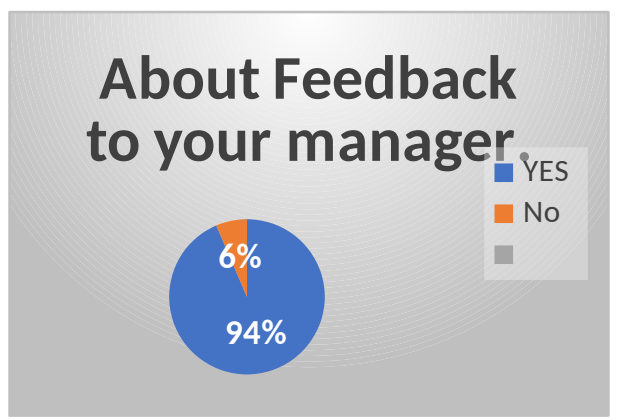

4. Has your manager the technical expertise required to effectively manage you? 


\section{Technical ex-} pertise required

to effectively

manage you.

5. Do you feel comfortable asking for help if you do not have the skills required to meet your goals?

\section{Comfortable} asking for help- yes

6. When you approach your manager with a problem, you trust that they will listen?

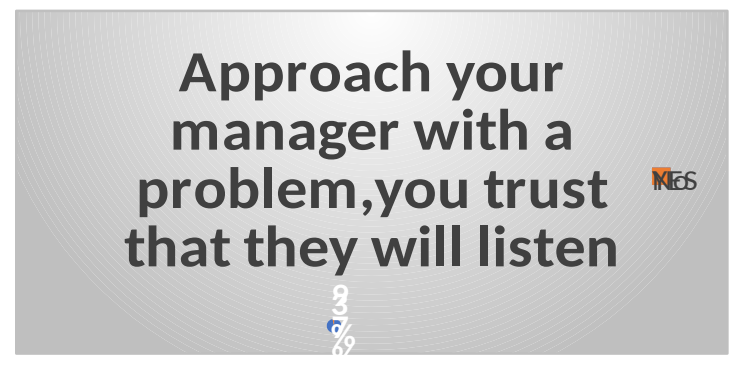

7. Do you know whom to talk to if you are having a problem that is not in your manager's domain?

\section{Clarity in reporting \\ a problem}

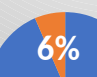

$94 \%$

8. Do you feel that there is at least one person at work who supports and encourages your development?

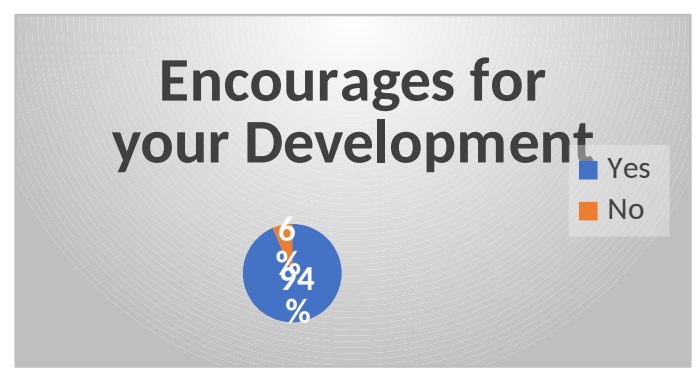

9. Members of your team are able to bring up problems and tough issues? 


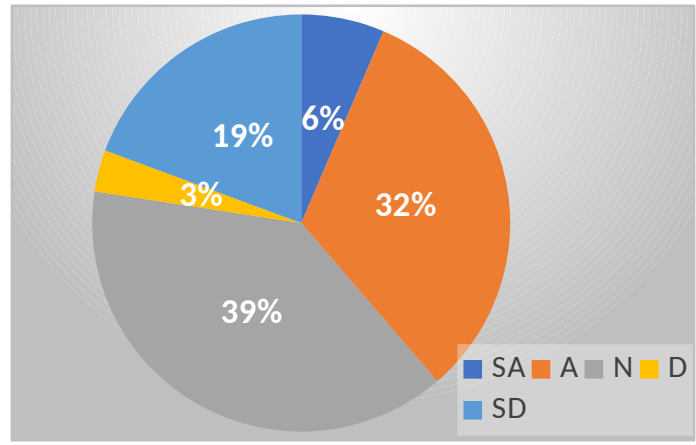

10. Are you comfortable sharing your opinion at all-hands meeting?

\section{Are you comfort- able sharing your opinion at all-hands} meeting?

$\square \mathrm{SA} \square \mathrm{A} \square \mathrm{N} \square \mathrm{D}$

SD

11. Are you proud to be an employee at your company?

Are you proud to be an employee at your company?
52
$\%$
$\mathrm{N} \quad \mathrm{D}$
SD

SA $\mathrm{A}$

12. Do you feel exhausted in the morning at the thought of another day at work?

\section{Do you feel exhausted in the morning at the thought of another day at work?}


13. Do you believe that generally, your workload is reasonable for your role?

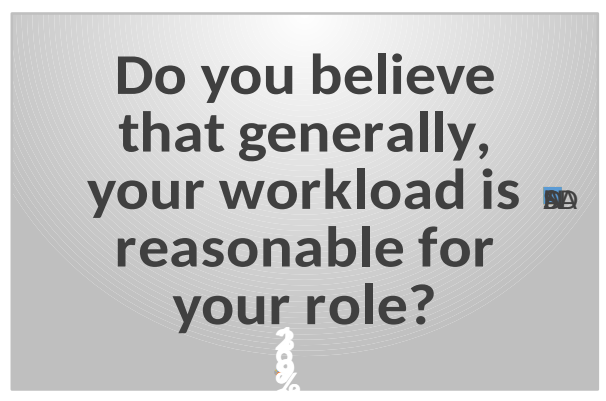

14. Do you feel recognized for your hard work and successes at work?

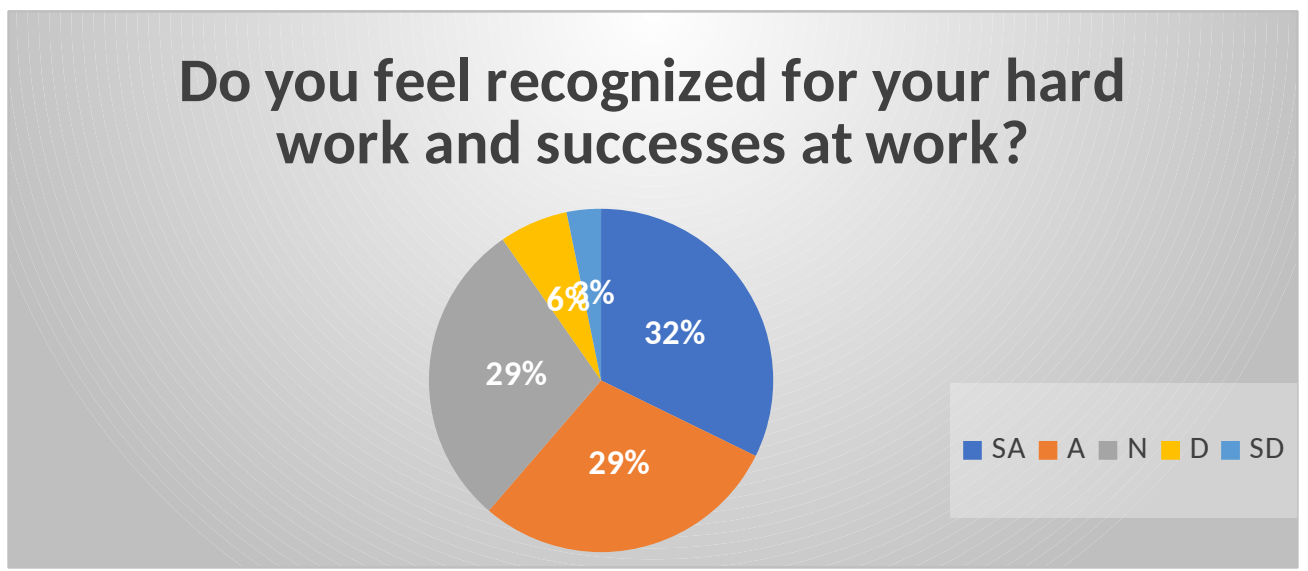

\section{Findings}

$>$ Most of the managers will demonstrate the interest in their employee's well-being.

$>$ All the managers of an Organization will set a clear expectations for the employees to perform well.

$>$ Almost all the employees will be comfortable in sharing feedback

$>$ Most of the managers have the technical expertise to manage the employees effectively

$>$ Most of the employees will feel comfortable in seeing help.

$>$ Most of the managers will try to listen their sub-ordinates if they approaches them with a problem.

$>$ All the employees are clearly aware whom they have to consult for any issue before it is being reported to manager.

$>$ Every employee will surely have one person in the organization in support of him.

$>$ First priority of the people say it is neutral about their team issues, Next to it people agree for it. Few people strongly disagree and rest say they agree and dis agree.

$>$ Most of the employees strongly agree that they comfortably share their opinion at all-hands meeting.

$>$ Most of the employees strongly agree that they are proud to be in their company.

$>$ Most of the employees dis agree that they don't feel exhausted in thought of thinking about the next day.

Most of the employees agree for their workload is reasonable for their role.

$>$ Most of the employees strongly agree that they will be recognized for their hard work.

\section{Conclusion}

Engaging employees has become very essential in today's pandemic situation due to COVID-19. Thinking of grasping the top position devoid of the support of employees would surely be a dream in this current situation of lockdown. Organizations know very well that engaged employees are the key to success in this hard time. That is why businesses must look forward to keeping their employees satisfied and encouraged through the engagement of employees during pandemic situations. Under the current circumstances, establishing employee engagement methods with the help of technology is essential for the growth of the organizations. Many companies nowadays are developing numerous employee engagement practices like virtual team meet-ups, virtual learning and development, conducting weekly alignment online session, 
webinars with industry experts, and also webinars for anxiety and stress, online team building activities, online family engagement practices, brainstorming, apology, and appreciation online session, shared content such as TED Talks, online books, online courses, live sessions for new-skill training, online communication exercise, online sharing best practices of maintaining health and hygiene, digital classrooms training modules, e-learning modules, online guidance for exercise and meditation, online recognition and acknowledgment of employees, online employee feedback, short online game session, virtual challenges and competitions, 5 minutes of informal talk, entire team gathers over video conference for lunch, online counseling sessions, and social interactions in the virtual office. These kinds of engagement practices boost the morale of the employees and employees feel motivated and committed towards the organization in this pandemic situation due to corona virus.

\section{References}

[1] Chen Y. Relationships among Service Orientation, Job Satisfaction, and Organizational Commitment in the International Tourist Hotel Industry. Journal of American Academy of Business. 2010. 11 (2). 7182

[2] Bailey AA, Albassami F, Al-Meshal S. The roles of employee job satisfaction and organizational commitment in the internal marketing-employee bank identification relationship. International Journal of Bank Marketing. 2016. 34 (6). 821-40

[3] Harter JK, Schmidt FL, Hayes TL. Business-unit level relationship between employee satisfaction, employee engagement, and business outcomes: A meta-analysis. Journal of Applied Psychology. 2002. 87. 268-79

[4] AmhalhalA, Anchor J, Dastgir S. The Effectiveness of the Use of Multiple Performance Measures: The Influence of Organizational Contingencies. London. Sage. 2015

[5] Hanaysha J. Testing the Effects of Employee Engagement, Work Environment, and Organizational Learning on Organizational Commitment. Procedia - Social and Behavioral Sciences. 2016. 229. 28997. https://doi.org/10.1016/j.sbspro.2016.07.139

[6] Welch M. The evolution of the employee engagement concept: communication implications'. Corporate Communications: An International Journal. 2011. 16. 328-46

[7] Paluku K. Employee Engagement and Organizational Performance of Retails Enterprises. American Journal of Industrial and Business Management. 2016. 6. 516-25

[8] Juan S, Yao L. Considering university governance: a preliminary investigation of employee engagement in higher educational institutions in Malaysia. In FGIC 1st Conference on Governance \& Integrity, 2017 "Innovation \& Sustainability Through Governance”, 224-232 